\title{
The Role of p38 MAPK in the Development of Diabetic Cardiomyopathy
}

\author{
Shudong Wang ${ }^{1}$, Lijuan Ding ${ }^{2}$, Honglei Ji ${ }^{1}$, Zheng $\mathrm{Xu}^{1}{ }^{1}$, Quan Liu ${ }^{1, *}$ and Yang Zheng ${ }^{1, *}$ \\ 1 Cardiovascular Center, The First Hospital of Jilin University, Changchun 130021, China; \\ wangshudong816@163.com (S.W.); wsd816@163.com (H.J.); wsxuzheng@163.com (Z.X.) \\ 2 Department of Radiation Oncology, the First Hospital of Jilin University, Changchun 130021, China; \\ juanjuan1693@163.com \\ * Correspondence: liuquan@jlu.edu.cn (Q.L.); zhengyang@jlu.edu.cn (Y.Z.); \\ Tel.: +86-431-8878-3787 (Q.L.); +86-431-8878-2217 (Y.Z.)
}

Academic Editor: Lu Cai

Received: 30 May 2016; Accepted: 24 June 2016; Published: 30 June 2016

\begin{abstract}
Diabetic cardiomyopathy (DCM) is a major complication of diabetes that contributes to an increase in mortality. A number of mechanisms potentially explain the development of DCM including oxidative stress, inflammation and extracellular fibrosis. Mitogen-activated protein kinase (MAPK)-mediated signaling pathways are common among these pathogenic responses. Among the diverse array of kinases, extensive attention has been given to p38 MAPK due to its capacity for promoting or inhibiting the translation of target genes. Growing evidence has indicated that p38 MAPK is aberrantly expressed in the cardiovascular system, including the heart, under both experimental and clinical diabetic conditions and, furthermore, inhibition of p38 MAPK activation in transgenic animal model or with its pharmacologic inhibitor significantly prevents the development of DCM, implicating p38 MAPK as a novel diagnostic indicator and therapeutic target for DCM. This review summarizes our current knowledge base to provide an overview of the impact of p38 MAPK signaling in diabetes-induced cardiac remodeling and dysfunction.
\end{abstract}

Keywords: diabetic cardiomyopathy; p38 MAPK; cardiac dysfunction; microRNAs

\section{Introduction}

Diabetes mellitus remains a worldwide health problem, and is associated with a high rate of mortality, primarily as a consequence of cardiovascular complications. The diabetic complications of type 1 diabetes mellitus (T1DM) and type 2 diabetes mellitus (T2DM) have been extensively investigated. Diabetic cardiomyopathy (DCM) is a major diabetic complication. Diabetes-induced cardiovascular changes that lead to heart failure, which are independent of macro- or micro-vascular diseases, are believed to account for the high incidence of heart failure and mortality in diabetic patients $[1,2]$. DCM initially manifests as cardiac hypertrophy that can promulgate to the development of cardiac dysfunction, both in terms of diastolic and systolic function. A number of mechanisms have been proposed to explain how the diabetic environment stimulates the development of DCM, including mechanisms involving cardiac myocyte apoptosis [3,4], oxidative stress [2,5], inflammation [1] and remodeling [1]. For each of these pathogenic effects, mitogen-activated protein kinase (MAPK) signaling pathways are common denominator downstream targets. MAPKs, which include extracellular signal-regulated kinase 1/2 (ERK1/2), c-Jun N-terminal protein kinase (JNK), and p38 MAP kinase, regulate physiological and pathological processes [3]. MAPK pathways are upregulated with insulin resistance [6], cardiac hypertrophy [7,8] and heart failure [9-11]. Among the association links that have been established, the connection between p38 MAPK and DCM is the most 
extensively evaluated $[8,12-16]$. In this review, we summarize the current literature base to provide an overview of the roles of p38 MAPK in DCM.

\section{Structure and Molecular Biology of p38 Mitogen-Activated Protein Kinase (MAPK)}

Among the MAPKs, p38 MAPK is involved in a wide range of signaling pathways that stimulate a multitude of different biological functions [17]. The structure characteristics of p38 MAPK have recently been reviewed [17]. There are four isoforms in the p38 MAPK sub-family: p38 $\alpha, p 38 \beta, p 38 \gamma$ and p38 . The p38 MAPK isoforms are encoded by different genes and have different tissue-specific expression patterns. The p38 $\alpha$ is ubiquitously expressed at significant levels in most cell types, while the others display more tissue-specificity. The $\mathrm{p} 38 \beta \mathrm{MAPK}$ is highly expressed in the central nervous system and lung, p38 $\gamma$ MAPK is readily detected in skeletal muscles, and p38 MAPK is enriched in endocrine glands. Among the p38 MAPK isoforms found in healthy heart, $\mathrm{p} 38 \alpha$ is the major form; in which $\mathrm{p} 38 \beta$ shows low expression, and both $\mathrm{p} 38 \gamma$ and $\mathrm{p} 38 \delta$ are minor components $[18,19]$. The diversity and specificity of cellular outcomes is achieved by functionally distinct p38 MAPK isoforms [20], with p38 MAPK regulating both cell survival [21] and physiological hypertrophy [22]. Accumulating evidence has indicated that $\mathrm{p} 38 \alpha$ MAPK is essential for mammalian embryonic development, indicating a physiological role for this isoform [21,23]. Mice with a genetic deletion of the p38 $\beta$ MAPK survive and respond normally to inflammatory stimuli [24].

Akt activation is essential for hypertrophy responses to physiological stimuli [25]. Apoptosis signal-regulating kinase 1 (ASK1) null mice and cardiac specific p38 $\alpha$ MAPK deficient mice developed an exacerbated form of physiologically cardiac hypertrophy through increased Akt activity in response to swimming, as an exercise stimuli [22]. In contrast, mice with cardiac specific overexpression of p38 $\alpha$ MAPK display pathological hypertrophy in response to swimming [26]. Under inflammation or hypoxic conditions, the activation of $\mathrm{p} 38 \alpha$ MAPK can suppress $\mathrm{p} 38 \beta \mathrm{MAPK}$, indicating the cross-talk among isoforms $[27,28]$.

\section{Effect of p38 MAPK Activation on Hearts of Diabetic Individuals}

The p38 MAPK has been best described as having a key role in the pathophysiology of diabetes, particularly p38 $\alpha$ MAPK $[15,29]$. The diversity and specificity of cellular outcome was achieved by functionally distinct p38 MAPK isoforms under different stress. There is evidence that p38 MAPK is activated during inflammation and oxidative stress, apoptosis, hypertrophy and energy metabolic abnormalities [4,30-35].

\subsection{Inflammatory and Oxidative Stress Pathways}

As a member of the MAPK family, p38 MAPK is specifically activated by phosphorylation in response to stress stimuli. The specific inhibition of $\mathrm{p} 38 \alpha$ MAPK is necessary and sufficient to achieve anti-inflammatory efficacy, and p $38 \beta$ MAPK is not required for acute or chronic inflammatory responses [24]. Over the course of diabetes, several complications can occur, mostly due to hyperglycemia and elevated reactive oxygen species (ROS) production [36]. Complications include increased susceptibility to microbial infections and reduced capacity to clear the infection. In high glucose-containing medium or the hyperglycemic sera of T2DM, Wnt/ $\beta$-catenin and p38 MAPK pathways are upregulated to impair dendritic cell differentiation and maturation [37]. Dendritic cell dysfunction caused by hyperglycemia could be responsible for increased susceptibility of diabetic individuals to infection. A p38 MAPK specific inhibitor, SB203580, partially rescues the impairment of dendritic cell differentiation and maturation induced by hyperglycemic sera, indicating the potentially important role of p38 MAPK in dendritic cell function [37]. ROS can activate p38 MAPK; and, in turn, p38 MAPK regulates the production of ROS to generate a feed-forward loop [38]; therefore, suppression of p38 MAPK can block ROS generation [39]. 


\subsection{The Apoptotic Pathway}

Cardiomyopathy is a late consequence of initial diabetes-induced early cardiac responses. One of the key early cardiac responses is cardiomyocyte apoptosis [3,40]. Hyperglycemia-induced ROS can activate MAPK to either stimulate or inhibit apoptosis in cardiomyocytes, depending on the isoform stimulated [35]. For example, p38 $\alpha$ stimulation facilitates cardiomyocyte apoptosis [4]. In contrast, p38 $\beta$ stimulation is anti-apoptotic for cardiomyocytes [41]. Apoptosis mediated by p38 MAPK occurs through the upregulation of signal transducer and activator of transcription 1 (STAT1), C/EBP homologous protein (CHOP), focal adhesion kinase (FAK), similar to mothers against decapentaplegic homolog (SMAD), cytochrome c, nuclear factor (NF)- $\mathrm{kB}$, phosphatase and tensin homolog (PTEN), and p53 pathways [17]. Functions of the other isoforms of p38 MAPK are not well-understood and need to be more completely addressed in future studies.

\subsection{Pathological Hypertrophy}

Hypertrophy occurs through both physiological and pathological mechanisms. Cardiac hypertrophy commonly occurs in response to pathological conditions such as diabetes, hypertension and myocardial infarction from coronary artery disease, which eventually results to cardiac fibrosis, remodeling and cardiac dysfunction. The sustained activation of p38 MAPK can lead to cardiac hypertrophy and dysfunction [42,43]. As a mediator, p38 MAPK phosphorylates and activates the GATA4 transcription factor to promote myocyte cell hypertrophy [44,45]. In addition, p38 MAPK regulates myocyte enhancer factor 2 (MEF2) transcriptional regulatory proteins to control cardiac differentiation during development $[7,46]$.

\subsection{Energy Metabolism Pathway}

Fatty acid oxidation supplies greater than $50 \%$ of the energy needed for a normal adult heart to sustain contraction and metabolism, while glucose and lactate are the main energy sources for fetal hearts [47]. An unbalanced energy metabolism and myocardial lipid accumulation are early aberrant conditions in obese and insulin-resistant individuals [48]. Increased glucose uptake causes cardiac dysfunction, which is associated with the upregulation of p38 MAPK, as well as elevated ROS [42]. ROS upregulation in the diabetes can stimulate p38 MAPK and initiate mitochondrial dysfunction in cardiomyocytes [48]. Insulin receptor substrates 1 and 2 (IRS1 and IRS2) are activated to phosphorylate Akt, which regulates a variety of physiological functions involved with energy metabolism [49,50], myocardial growth [51] and survival [52].

The relationship between IRS1, IRS2, and p38 $\alpha$ MAPK has been investigated in a recent study. Cardiac myocyte-specific IRS1 and IRS2 double null mice exhibited down-regulation of Akt phosphorylation, along with cardiac dysfunction [50]. Furthermore, IRS1 and IRS2 protein levels and Akt phosphorylation were reduced, whereas p38 $\alpha$ MAPK phosphorylation was increased, in the hearts of high fat diet (HFD) and the leptin receptor deficient $(\mathrm{db} / \mathrm{db})$ mice, compared with control. These results revealed that $338 \alpha$ MAPK activation may be associated with reduction of IRS1 and IRS2 under diabetic or insulin resistant conditions. Next, the exact mechanisms whereby p38 $\alpha$ MAPK regulates expression of IRS1 and IRS2 were determined by in vitro studies. IRS1 and IRS2 decreased with chronic insulin treatment along with increased p38 $\alpha$ MAPK phosphorylation. Inhibition of p38 $\alpha$ MAPK completely prevented the down-regulation of IRS1 and IRS2. In addition, overexpression of p38 $\alpha$ MAPK downregulated IRS1 and IRS2 in a dose-dependent manner. The above results suggested that p38 activation was required for chronic insulin-induced IRS1 and IRS2 degradation and insulin resistance. [50]. In contrast, the overexpression of IRS1 or IRS2 attenuates p38 $\alpha$ MAPK-dependent cardiac damage. Taking these results together, p38 $\alpha$ MAPK mediates the effect of chronic insulin to promote insulin resistance by suppressing IRS1 and IRS2. 


\section{Protective Role of $\mathrm{p} 38 \beta$ MAPK in Diabetes}

The cardioprotective role of $\mathrm{p} 38 \beta$ MAPK was universal in different animal models. Activation of the p38 $\beta$ MAPK attenuated doxorubicin-induced cardiotoxicity [53]. In an ischemic heart damage model, ischemia-related stress increased ROS generation, which in turn activates p38 $\alpha$ MAPK to regulate p53 activity. Consequently, p53 activation inhibited p38 $\beta$ MAPK signaling cascade. This finding revealed a complex inter-relationship among p38 MAPK isoforms [28]. Similarly, under diabetic conditions, a few studies have demonstrated that $\mathrm{p} 38 \beta$ MAPK played an important role to protect against palmitate-induced endoplasmic reticulum stress and apoptosis in cardiac myocytes in vitro [41], and against palmitate-induced apoptotic effects in the heart of mice with fibroblast growth factor treatment [3].

In addition, the activation of $\mathrm{p} 38 \beta$ MAPK was also required for mediating the protective effect of stromal cell-derived factor- $1 \beta$ (SDF-1 $\beta$ ) on cardiac myocytes exposed to lipotoxicity in vitro and diabetes in vivo [41]. In an in vitro study, inhibition p38 MAPK by SB203580 did not affect palmitate-induced cell death but completely abolished the protective effect of SDF-1 $\beta$ on palmitate-induced cell death. Since the SB203580 unselectively blocks the $\alpha$ and $\beta$ of p38 MAPK, p38 $\beta$ MAPK siRNA was used to define the specific role of $\mathrm{p} 38 \beta$ MAPK in the protection of SDF- $1 \beta$ from palmitate-induced cell death since the protective effect of SDF-1 $\beta$ on palmitate-induced cell death was completely abolished by p38 $\beta$ MAPK siRNA. In summary, p38 MAPK can protect from and mediate various diabetes-induced pathological changes leading to DCM, depending on $\beta$ isoform is activated.

\section{The Inhibition of p38 MAPK Is Beneficial for Diabetic Complications}

The inactivation or inhibition of p38 MAPK restores cardiac function in diabetes $[15,29]$. Atorvastatin, as a lipophilic statin, exerts beneficial effects in the prevention of cardiovascular disease and improves outcomes in patients with diabetes or obesity. In DCM, atorvastatin improves cardiac function by reducing inflammation and suppressing the activation of p38 MAPK [54]. Similar results were obtained in the kidneys of diabetic rats [55]. Atorvastatin treatment downregulated osteopontin (OPN) expression and improved kidney function along with suppressed phosphorylation of p38 MAPK. In an in vitro study, Madin-Darby canine kidney epithelial cells were pretreated with the pharmacological inhibitor of p38 MAPK (SB203580) or the pharmacological activator of p38 MAPK (phorbol 12-myristate 13-acetate, PMA). SB203580 inhibited glucose-induced p38 MAPK phosphorylation and correspondingly repressed OPN expression, while PMA increased the phosphorylation of p38 and the expression of OPN [55]. Gallic acid (GA, 3,4,5-trihydroxybenzoic acid) prevented the development of diabetic nephropathy by inhibiting p38 MAPK activation in high fat diet/STZ induced T2DM rats and cultured renal proximal tubular epithelial cells [56].

Insulin therapy is a primary method to treat diabetes, which can further prevent diabetic cardiac damage [57]. Early intensive insulin treatment (at the initial phase) and the attainment of good glycemic control reduce renal molecular pathways associated with epigenetic metabolic memory with the decline of p38 MAPK [58]. The above research displayed that p38 MAPK was involved in DCM and diabetic nephropathy, and suppression or downregulation of p38 MAPK improves cardiac function and kidney function. However, the protective effects are direct or indirect need to be further addressed.

\subsection{Specific Inhibition of $p 38$ MAPK with Inhibitors}

The inhibition of p38 MAPK has been achieved using specific inhibitors, and genetic deletion, as shown in Table 1. Different inhibitors of p38 MAPK that target each of the four isoforms or inhibitors targeting a combination of these isoforms are available. The use of these inhibitors results in diverse effects. SB 203580 as an inhibitor of p38 MAPK does not distinguish between p38 $\alpha$ and p38 $\beta$ and also reacts with other cellular targets including Akt and c-Raf [59]. SB 202190 and PD169316 blocks p38 $\alpha$ and p38 $\beta$, respectively. BIRB 0796 can suppress all four isoforms [59]. In streptozotocin (STZ)-induced diabetic cardiomyopathy, the inhibition of p38 MAPK with SB 203580 (1 mg/kg of body weight daily, beginning at the onset of diabetes and continued for eight weeks), improved cardiac function, which is associated with reduced cardiac inflammation characterized by reduced myocardial tissue necrosis 
factor $\alpha$ (TNF- $\alpha$ ), interleukin-1 $\beta$ (IL-1 $\beta$ ), and interleukin-6 (IL-6) levels [15]. In addition, the cardiac transforming growth factor- $\beta$ (TGF- $\beta$ ) was decreased by the SB203580. These results revealed that inhibition of p38 MAPK by its specific inhibitor can prevents DCM in T1DM animal model.

Table 1. Inhibitors of p38 MAPK isoforms.

\begin{tabular}{ccccc}
\hline Inhibitors & Isoforms & Model & Response & References \\
\hline SB203580 & $\alpha, \beta$ & $\begin{array}{c}\text { Multiple injections of STZ }(50 \mathrm{mg} / \mathrm{kg} \\
\text { i.p. for five days) in C57 / BL6 mice }\end{array}$ & Improved cardiac function \\
\hline SB202190 & $\alpha, \beta$ & $\begin{array}{c}\text { Single injection of STZ }(65 \mathrm{mg} / \mathrm{kg} \text { i.p. }) \\
\text { in rats }\end{array}$ & Prevented cardiomyocyte apoptosis & [60] \\
\hline PD169316 & $\alpha, \beta$ & $\begin{array}{c}\text { Human adult ventricular } \\
\text { cardiomyocytes treated with palmitate }\end{array}$ & Increased vasorelaxation \\
\hline BIRB 0796 & $\alpha, \beta, \gamma$ and, $\delta$ & $\begin{array}{c}\text { Cardiac myofibroblasts treated with } \\
\text { 10 ng/mL of IL-1 } \alpha \text { for six hours }\end{array}$ & $\begin{array}{c}\text { Reduced inflammatory } \\
\text { cytokine release }\end{array}$ \\
\hline
\end{tabular}

p38 MAPK, p38 mitogen-activated protein kinase; IL, interleukin; i.p., intraperitoneal injection; STZ, streptozocin.

In human adult ventricular cardiomyocytes (AC16 cells) exposed to high concentrations of palmitate to mimic diabetic lipotoxicity in the heart [4], palmitate induced the dose-dependent activation of $\mathrm{p} 38 \mathrm{MAPK}$, with total p38MAPK levels remaining unchanged. The inhibition of p38MAPK with PD169316, a nonspecific inhibitor of $\mathrm{p} 38$ MAPK $\alpha$ and $\beta$, beginning at two hours prior to exposure to palmitate and continued for $16 \mathrm{~h}$, reduced apoptosis induced by palmitate. The suppression of phosphorylated p38 $\alpha$ MAPK with a specific siRNA against p38 $\alpha$ MAPK attenuated cardiomyocyte apoptosis [4]. In a similar experimental condition, the inhibition of $\mathrm{p} 38 \beta$ MAPK with its specific siRNA abolished protective effect of stromal cell-derived factor-1 (SDF-1) on palmitate-induced apoptosis [41]. In addition, SB 202190 significantly decreases high glucose-induced inflammation [62].

In term of p38 MAPK inhibitor BIRB 0796, there was only one study showing that BIRB 0796 $(1 \mu \mathrm{M}$, beginning at one hour prior to exposure to IL-1 $\alpha$ ) protected against excessive extracellular matrix protein accumulation in the myocardium during post myocardial-infarction remodeling [63]. However, there is no study with it directly to investigate the role of p38 MAPK on DCM yet; therefore, whether BIRB can be used to prevent against DCM remains further investigated.

\subsection{Suppression of $p 38 \alpha$ MAPK in Dominant-Negative Mutant of Transgenic Model}

Since the p38 MAPK inhibitor used in above studies does not distinguish between p38 $\alpha$ and p38 $\beta$, which isoform of p38 MAPK plays the role remains unclear. The specific isoforms of p38 $\alpha$ or p38 $\beta$ transgenic models were used to investigate the role of $\mathrm{p} 38 \alpha$ or $\mathrm{p} 38 \beta$ MAPK. The loss of $\mathrm{p} 38 \alpha$ MAPK caused embryonic death, therefore, p38 $\alpha$ MAPK knockout mice were not available to clarify the role of p38 MAPK in DCM. Accordingly, p38 MAPK transgenic mice with cardiac-specific overexpression of a dominant-negative mutant of p38 $\alpha$ MAPK (TG DN p38 $\alpha$ MAPK) has been used to investigate the role of $\mathrm{p} 38 \alpha$ MAPK in a STZ-induced DCM [29]. In the diabetic mouse model, the expression of molecular markers of cardiomyocyte hypertrophy (ANP) and fibrosis (TGF- $\beta$ and collagen III), as well as apoptotic cardiomyocytes, were elevated. These changes were markedly attenuated in transgenic mice. Cardiac dysfunction (reduced fractional shortening) induced by diabetes in WT mice was restored by TG DN p38 $\alpha$ MAPK mice. These findings indicate that the p38 $\alpha$ MAPK isoform plays an important role in cardiac damage associated with DCM in T1DM animal models.

T2DM is the most widespread metabolic disease in the world [64]. Further research is needed with p38 MAPK inhibitor or/and dominant-negative mutant of p38 $\alpha$ MAPK transgenic mouse model of T2DM to fully understand the roles of p38 MAPK. Taken together, p38 $\alpha$ MAPK is involved in the development of DCM, and p38 $\beta$ MAPK is required for the anti-apoptosis effects of inhibitors and gene deletion. Due to the existence of the four isoforms of p38 MAPK, using specific siRNAs against individual isoforms may be the best method to investigate the exact effect of each isoform for mechanistic evaluations. 


\section{Suppression of the Downstream of p38 MAPK}

Clinical studies with p38 MAPK inhibitors have shown hepatotoxicity related to a p38 MAPK-mediated feed-back loop involving TGF- $\beta$ activated kinase 1 (TAK1) and JNK activation $[65,66]$. The inhibition of the downstream of $\mathrm{p} 38$ MAPK may provide alternative targets including MAPKAPK-2 (MK2) and MAPKAPK-3 (MK3) to minimize or eliminate this complication. In most cells and tissues, MK3 expression is very low compared to MK2 expression. MK2 exacerbates inflammatory processes, and is necessary for the sustained activation of NF- $\mathrm{KB}$, a central transcription factor in inflammation that has been reported to be involved in the development of insulin resistance [67]. MK2 is activated in the liver and heart. In diabetes, the suppression or deficiency of MK2 improves glucose tolerance and insulin sensitivity in obese mice [68-71]. The sarcoendoplasmic reticulum $\mathrm{Ca}^{2+}$-ATPase 2a (SERCA2a) is responsible for $\mathrm{Ca}^{2+}$ reuptake into the sarcoplasmic reticulum, and has been directly linked to contractility and alterations in excitation-contraction coupling [72]. Cardiac dysfunction in DCM has been shown to be associated with the downregulation of SERCA2a [73,74], similar to what is shown in ischemic cardiomyopathy $[75,76]$ and stress-induced cardiomyopathy [77]. Protein kinase MK2, a p38MAPK downstream target, has been studied as a mediator in the development of DCM [30]. Five-week-old male control mice $\left(\mathrm{MK}^{+/+}\right)$and $\mathrm{MK} 2$ whole-body null mice $\left(\mathrm{MK}^{-/-}\right)$ administered with STZ injections to induce diabetes have been observed for 15 weeks after the injections were initiated. The inhibition of MK2 improves insulin sensitivity and dyslipidemia. MK2 ${ }^{-/-}$mice exhibited improved cardiac function concomitant with normalized SERCA2a expression and phospholamban (PLB) phosphorylation. It is worth mentioning that the impaired metabolism of energy-providing substrates and myocardial lipid accumulation are early abnormalities in obese and insulin-resistant individuals. Free fatty acid (FFA) levels were elevated in positive control wild type diabetic mice, while these levels returned toward non-diabetic negative control mice levels in diabetic $\mathrm{MK} 2^{-/-}$mice. Furthermore, $\mathrm{MK} 2^{-/-}$mice revealed no changes in FFA metabolic rates, while diabetic positive control mice $\left(\mathrm{MK}^{+/+}\right)$displayed enhanced exogenous FFA oxidation and fat esterification for storage. MK2 can directly regulate the expression of SERCA2a [72]. However, the deletion of MK2 prevents diabetes-induced cardiac dysfunction that may be related to improvements in systemic glucose tolerance and lipid profiles. In a short-term evaluation of diabetic nephropathy, it was found that $\mathrm{MK} 2^{-/-}$mice were not protected against renal hyperfiltration or elevations in glucose concentrations [78]. These different effects may be associated with a divergence in mechanisms across organs or across the duration of diabetes. Future studies using the cardiac specific deletion of MK2 are needed to investigate its beneficial effects in diabetic and obesity models that result directly from cardiomyocyte MK2 expression.

The inhibition of MK2/3 with the inhibitor, compound 28, improves glucose homeostasis in obese mice [70]. Compound 28 has additive beneficial metabolic effects with metformin in $\mathrm{db} / \mathrm{db}$ mice, indicating the novel effect of MK2/3 inhibition. In light of the possible multiple beneficial effects of MK2/3 inhibition in the liver, effects on other organs need to be assessed. Of interest, the complete whole body deletion of MK2 aggravates the consequences of metabolic disorder in a high-fat diet induced obesity mouse model, due to enhancement of the pro-inflammatory polarization of adipose tissue macrophages and decreased expression of glucose transporter type (GLUT4) [71]. Compound 28 does not reduce GLUT4 levels, which may reveal differences between global genetic deletion and inhibition using a pharmacological inhibitor.

Taken together, MK2 or MK2/3 represents new potential therapeutic targets to T1DM-induced cardiac dysfunction and improve insulin sensitivity in T2DM. Differential effects between the genetic model and inhibitors needs to be reconciled as part of the attempt to translate these findings to clinic. Apart from MK2 and MK2/3, several other kinases activated by the p38 MAPK pathway are involved in the development of DCM, and these kinases include CREB, ATF1, NF- $\mathrm{kB}$, and p53 [20]. The inhibition of these genes can protect against diabetic complications $[79,80]$. 


\section{MicroRNAs Associated with p38 MAPK Activity in Diabetes}

Emerging evidence supports roles for microRNA (miRNA) in heart disease, including the development of cardiac hypertrophy [81,82], myocardial ischemia [83], cardiac dysfunction [84] and metabolic stress [85]. miRNAs inhibit protein expression through binding to the 3 'untranslated region (UTR) of target genes. The functions of these miRNAs can provide the central regulation of gene expression under conditions of stress (refer to reviews [86,87]). miRNAs are involved in the activation of p38 MAPK in a neonatal rat cardiomyocyte hypertrophy model induced by high glucose (HG) [88]. As shown in Table 2, p38 MAPK can be regulated as a target of multiple miRNAs [89]. Therefore, whether $\mathrm{p} 38$ MAPK related miRNAs are also involved in the pathological and intervention procedure of DCM is also interestingly discussed here.

Table 2. MicroRNAs involved in p38 MAPK activity.

\begin{tabular}{ccccc}
\hline MicroRNA & Location & Model & Response & References \\
\hline miR-373 & Downstream & $\begin{array}{c}\text { Single injection of STZ (150 mg/kg i.p.) } \\
\text { in C57/BL6 mice }\end{array}$ & Prevent cardiomyocyte hypertrophy & [88] \\
\hline miR-23b & Downstream & $\begin{array}{c}\text { LV of T2D patients and cardiomyocytes } \\
\text { from rat high glucose-induced model }\end{array}$ & $\begin{array}{c}\text { Prevent cardiomyocyte hypertrophy } \\
\text { [90] }\end{array}$ \\
\hline miR-143 & Downstream & $\begin{array}{c}\text { Primary rat cardiomyocytes exposed to } \\
\text { adipose tissue from T2D patients }\end{array}$ & $\begin{array}{c}\text { Increase cardiomyocyte } \\
\text { insulin resistance }\end{array}$ \\
\hline miR-24 & Upstream & $\begin{array}{c}\text { T2D patients and } \\
\text { Goto-Kakizaki (GK) rat }\end{array}$ & Prevent cardiomyocyte apoptosis \\
\hline miR-21 & Upstream & $\begin{array}{c}\text { Rat cardiac fibroblasts with high } \\
\text { glucose treatment (in vitro) }\end{array}$ & Prevent cardiac fibrosis \\
\hline
\end{tabular}

Location refers to being upstream or downstream of p38 MAPK; i.p., intraperitoneal injection; LV-left ventricle; STZ, streptozotocin; T2D, Type-2 diabetes.

In T1DM mice and in primary neonatal rat myocytes treated with HG, p38 MAPK upregulation occurs in association with the increased expression of hypertrophy markers ANP and brain natriuretic peptide (BNP) [88]. A miRNA microarray analysis revealed that miR-21, miR-208a and miR-705 are upregulated, while miR-29, miR-1, miR-373, miR-143, miR-20a, and miR-220b are downregulated in diabetic mice, compared to control mice. The upregulation of miR-373, which was achieved by transfecting cardiomyocytes with a miR-373 mimic, reduces hypertrophy and the expression of MEF2c, a transcription factor-associated myocardial hypertrophy. Inhibiting p38 MAPK using a specific inhibitor, SB203580, significantly reduces the expression of miR-373 and MEF2c, indictating that miR-373 is transcriptionally regulated by p38 MAPK.

miRNA-23b has recently been associated with the development of immune diseases [94] and in neovascularization during age-related macular degeneration [95] due to its key functions of cell cycle regulation, migration, apoptosis and differentiation [96]. miR-23b was downregulated in diabetic hearts and in cardiomyocytes following exposure to HG [90]. miR-23b overexpression attenuates HG-induced myocyte hypertrophy. In contrast, miR-23b reduction by treatment with a specific inhibitor induced cardiomyocyte hypertrophy. The suppression of p38 MAPK with SB203580 markedly increased miR-23b to reduce cardiomyocyte hypertrophy.

miR-143 expression is increased in DCM, leading to the inhibition of Akt signaling activity [91,97]. In the HL-1 cell line, insulin-mediated glucose uptake is lowered by $25 \%$ in cells expressing pre-miR- 143 vs. control miRNA. The inhibition of miR-143 using the LNA inhibitor for miR-143 protected against the detrimental effects of DCM. The pharmacological p38 MAPK inhibitor SB203580 abolished the induction of miR-143, demonstrating that the induction of miR-143 is p38-dependent [91].

miR-24 is down-regulated in ischemic cardiomyopathy [98] and diabetes [99]. miR-24 suppresses cardiomyocyte apoptosis in a myocardial infarction model [98]. A novel mechanism for the development of DCM has been proposed, in which miR-24 is downregulated following the hyperglycemia-induced activation of c-Myc. Whether insulin resistance and hyperinsulinemia also mediate the expression or stability of miR-24 in diabetes remains unclear [100]. It has been reported that p38 MAPK is a direct target of miR-24 in humans [101] and in mouse models [92]. In Goto-Kakizaki rats, increased p38 
MAPK levels were observed in an animal model of spontaneous T2DM. miR-24 was downregulated in muscles of Goto-Kakizaki rats, while the activation of the upstream of p38 MAK has been explored by testing relative luciferase activity. miR-24 replacement therapy is a promising avenue for diabetic patients. However, future studies in large animal models are warranted.

miR-21 prevents ischemia/reperfusion (I/R)- and $\mathrm{H}_{2} \mathrm{O}_{2}$-induced cardiomyocyte apoptosis by suppressing the Fas ligand and activating Akt [102]. Furthermore, miR-21 inhibition reduces p38 MAPK activation in A-498 cells [103]. It is worth mentioning that miR-21 increased significantly in a time-dependent manner in cardiac fibroblasts treated with high levels of glucose, and this increase is accompanied by an increase in p38 MAPK [93]. This implicates miR-21 as being involved in diabetes-induced cardiac fibrosis. The inhibition of miR-21 blocks the elevation of phosphorylated p38 MAPK to decrease fibrosis in the setting of DCM, demonstrating a direct role for miR-21.

In summary, a variety of miRNAs have been found to be involved in the p38 MAPK-mediated cardiac effects of DCM, where they act as either up-stream regulators or down-stream targets. The role of miRNAs in DCM is a burgeoning topic.

\section{Conclusions}

There is increasing evidence that p38 MAPK plays a significant role in diabetic cardiomyopathy, including the regulation of diabetic complications such as cardiac hypertrophy, fibrosis, and apoptosis (Figure 1). Further work is needed to understand the complete role of p38 MAPK in the pathogenesis of cardiac remodeling and dysfunction before this knowledge can be applied in translational research, in order to assess the therapeutic efficacy of using p38 MAPK inhibitors for targeting diabetic complications.

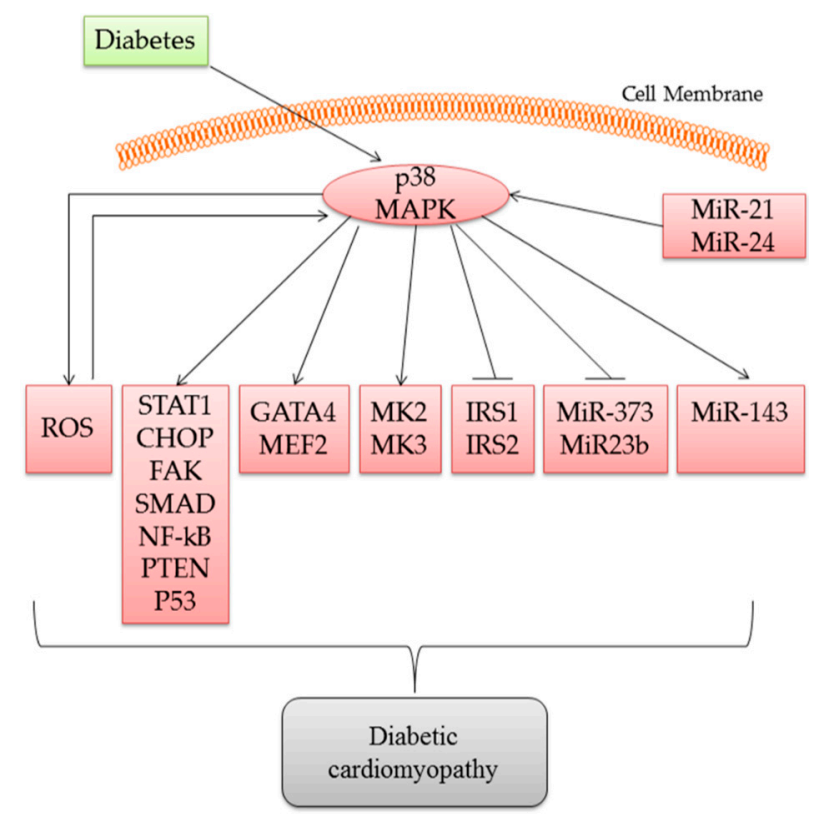

Figure 1. Activation of $\mathrm{p} 38$ Mitogen-activated protein kinase (MAPK) regulates a variety of pathological processes through multiple different signaling pathways.

Acknowledgments: Cited studies from the authors' laboratories were supported in part by the grants awarded by National Natural Science Foundation of China (No. 81370318, to Yang Zheng; and No. 81470495, to Honglei Ji and Jilin Province Science and Technology Development Project (20150414034GH).

Author Contributions: Yang Zheng and Quan Liu conceived of and designed the review. Lijuan Ding, Honglei Ji, and Zheng Xu consulted literature. Shudong Wang, Yang Zheng and Quan Liu wrote the paper.

Conflicts of Interest: The authors declare not conflict of interest. 


\section{Abbreviations}

$\begin{array}{ll}\text { ANP } & \text { Atrium natriuretic peptide } \\ \text { ASK1 } & \text { Apoptosis signal-regulating kinase 1 } \\ \text { BNP } & \text { Brain natriuretic peptide } \\ \text { CHOP } & \text { C/EBP homologous protein } \\ \text { DCM } & \text { Diabetic cardiomyopathy } \\ \text { ERK1/2 } & \text { Extracellular signal-regulated kinase 1/2 } \\ \text { FAK } & \text { Focal adhesion kinase } \\ \text { FFA } & \text { Free fatty acid } \\ \text { GLUT4 } & \text { Glucose transporter type } 4 \\ \text { HG } & \text { High glucose } \\ \text { IL-6 } & \text { Interleukin-6 } \\ \text { IRS1 } & \text { Insulin receptor substrates 1 } \\ \text { IRS2 } & \text { Insulin receptor substrates 2 } \\ \text { JNK } & \text { C-Jun N-terminal protein kinase } \\ \text { I.P } & \text { Intraperitoneal injection } \\ \text { MEF2 } & \text { Myocyte enhancer factor 2 } \\ \text { MAPK } & \text { Mitogen-activated protein kinase } \\ \text { MK2 } & \text { MAPKAPK-2 } \\ \text { MK3 } & \text { MAPKAPK-3 } \\ \text { NF- } k B & \text { Nuclear factor- } k B \\ \text { P38 MAPK } & \text { P38 MAP kinase } \\ \text { PTEN } & \text { Phosphatase and tensin homolog } \\ \text { ROS } & \text { Reactive oxygen species } \\ \text { SERCA2a } & \text { Sarcoendoplasmic reticulum Ca }{ }^{2+} \text {-ATPase 2a } \\ \text { SDF-1 } \beta & \text { Stromal cell-derived factor-1 } \beta \\ \text { SMAD } & \text { Similar to mothers against decapentaplegic homolog } \\ \text { STAT1 } & \text { Signal transducer and activator of transcription 1 } \\ \text { STZ } & \text { Streptozotocin } \\ \text { T1DM } & \text { Type 1 diabetes mellitus } \\ \text { T2DM } & \text { Type 2 diabetes mellitus } \\ \text { TNF- } \alpha & \text { Tissue necrosis factor } \alpha \\ \text { TGF- } \beta & \text { Transforming growth factor- } \beta \\ & \\ & \end{array}$

\section{References}

1. Zhang, Z.; Wang, S.; Zhou, S.; Yan, X.; Wang, Y.; Chen, J.; Mellen, N.; Kong, M.; Gu, J.; Tan, Y.; et al. Sulforaphane prevents the development of cardiomyopathy in type 2 diabetic mice probably by reversing oxidative stress-induced inhibition of LKB1/AMPK pathway. J. Mol. Cell. Cardiol. 2014, 77, 42-52.

2. Bai, Y.; Cui, W.; Xin, Y.; Miao, X.; Barati, M.T.; Zhang, C.; Chen, Q.; Tan, Y.; Cui, T.; Zheng, Y.; et al. Prevention by sulforaphane of diabetic cardiomyopathy is associated with up-regulation of NRF2 expression and transcription activation. J. Mol. Cell. Cardiol. 2013, 57, 82-95.

3. Zhang, C.; Huang, Z.; Gu, J.; Yan, X.; Lu, X.; Zhou, S.; Wang, S.; Shao, M.; Zhang, F.; Cheng, P.; et al. Fibroblast growth factor 21 protects the heart from apoptosis in a diabetic mouse model via extracellular signal-regulated kinase 1/2-dependent signalling pathway. Diabetologia 2015, 58, 1937-1948.

4. Oh, C.C.; Nguy, M.Q.; Schwenke, D.C.; Migrino, R.Q.; Thornburg, K.; Reaven, P. P38 $\alpha$ mitogen-activated kinase mediates cardiomyocyte apoptosis induced by palmitate. Biochem. Biophys. Res. Commun. 2014, 450, 628-633.

5. Zhang, C.; Zhang, L.; Chen, S.; Feng, B.; Lu, X.; Bai, Y.; Liang, G.; Tan, Y.; Shao, M.; Skibba, M.; et al. The prevention of diabetic cardiomyopathy by non-mitogenic acidic fibroblast growth factor is probably mediated by the suppression of oxidative stress and damage. PLOS ONE 2013, 8, e82287.

6. Zhao, Y.; Tang, Z.; Zhu, X.; Wang, X.; Wang, C.; Zhang, W.; Xia, N.; Wang, S.; Huang, J.; Cui, S. TAB3 involves in hepatic insulin resistance through activation of MAPK pathway. Gen. Comp. Endocrinol. 2015, 224, $228-234$.

7. Dadson, K.; Turdi, S.; Hashemi, S.; Zhao, J.; Polidovitch, N.; Beca, S.; Backx, P.H.; McDermott, J.C.; Sweeney, G. Adiponectin is required for cardiac MEF2 activation during pressure overload induced hypertrophy. J. Mol. Cell. Cardiol. 2015, 86, 102-109.

8. Gao, Y.; Kang, L.; Li, C.; Wang, X.; Sun, C.; Li, Q.; Liu, R.; Wang, J. Resveratrol ameliorates diabetes-induced cardiac dysfunction through AT1R-ERK/p38 MAPK signaling pathway. Cardiovasc. Toxicol. 2016, 16, 130-137. 
9. Thandavarayan, R.A.; Giridharan, V.V.; Arumugam, S.; Suzuki, K.; Ko, K.M.; Krishnamurthy, P.; Watanabe, K.; Konishi, T. Schisandrin b prevents doxorubicin induced cardiac dysfunction by modulation of DNA damage, oxidative stress and inflammation through inhibition of MAPK/p53 signaling. PLoS ONE 2015, 10, e0119214.

10. Kim, M.; Oh, J.K.; Sakata, S.; Liang, I.; Park, W.; Hajjar, R.J.; Lebeche, D. Role of resistin in cardiac contractility and hypertrophy. J. Mol. Cell. Cardiol. 2008, 45, 270-280.

11. Pan, Y.; Wang, Y.; Zhao, Y.; Peng, K.; Li, W.; Wang, Y.; Zhang, J.; Zhou, S.; Liu, Q.; Li, X.; et al. Inhibition of JNK phosphorylation by a novel curcumin analog prevents high glucose-induced inflammation and apoptosis in cardiomyocytes and the development of diabetic cardiomyopathy. Diabetes 2014, 63, 3497-3511.

12. Yan, Z.; Ni, Y.; Wang, P.; Chen, J.; He, H.; Sun, J.; Cao, T.; Chen, J.; Zhao, Z.; Luo, Z.; et al. Peroxisome proliferator-activated receptor delta protects against obesity-related glomerulopathy through the p38 MAPK pathway. Obesity 2013, 21, 538-545.

13. Zhu, S.; Yang, Y.; Hu, J.; Qian, L.; Jiang, Y.; Li, X.; Yang, Q.; Bai, H.; Chen, Q. Wld(s) ameliorates renal injury in a type 1 diabetic mouse model. Am. J. Physiol. Ren. Physiol. 2014, 306, F1348-F1356.

14. Cao, L.; Qin, X.; Peterson, M.R.; Haller, S.E.; Wilson, K.A.; Hu, N.; Lin, X.; Nair, S.; Ren, J.; He, G. CARD9 knockout ameliorates myocardial dysfunction associated with high fat diet-induced obesity. J. Mol. Cell. Cardiol. 2016, 92, 185-195.

15. Westermann, D.; Rutschow, S.; van Linthout, S.; Linderer, A.; Bucker-Gartner, C.; Sobirey, M.; Riad, A.; Pauschinger, M.; Schultheiss, H.P.; Tschope, C. Inhibition of p38 mitogen-activated protein kinase attenuates left ventricular dysfunction by mediating pro-inflammatory cardiac cytokine levels in a mouse model of diabetes mellitus. Diabetologia 2006, 49, 2507-2513.

16. Kassan, M.; Choi, S.K.; Galan, M.; Lee, Y.H.; Trebak, M.; Matrougui, K. Enhanced p22phox expression impairs vascular function through p38 and ERK1/2 map kinase-dependent mechanisms in type 2 diabetic mice. Am. J. Physiol. Heart Circ. Physiol. 2014, 306, H972-H980.

17. Yokota, T.; Wang, Y. P38 map kinases in the heart. Gene 2016, 575, 369-376.

18. Lemke, L.E.; Bloem, L.J.; Fouts, R.; Esterman, M.; Sandusky, G.; Vlahos, C.J. Decreased p38 MAPK activity in end-stage failing human myocardium: P38 MAPK $\alpha$ is the predominant isoform expressed in human heart. J. Mol. Cell. Cardiol. 2001, 33, 1527-1540.

19. Koivisto, E.; Kaikkonen, L.; Tokola, H.; Pikkarainen, S.; Aro, J.; Pennanen, H.; Karvonen, T.; Rysa, J.; Kerkela, R.; Ruskoaho, H. Distinct regulation of b-type natriuretic peptide transcription by p38 MAPK isoforms. Mol. Cell. Endocrinol. 2011, 338, 18-27.

20. Cuadrado, A.; Nebreda, A.R. Mechanisms and functions of p38 MAPK signalling. Biochem. J. 2010, 429, 403-417.

21. Allen, M.; Svensson, L.; Roach, M.; Hambor, J.; McNeish, J.; Gabel, C.A. Deficiency of the stress kinase p38 $\alpha$ results in embryonic lethality: Characterization of the kinase dependence of stress responses of enzyme-deficient embryonic stem cells. J. Exp. Med. 2000, 191, 859-870.

22. Taniike, M.; Yamaguchi, O.; Tsujimoto, I.; Hikoso, S.; Takeda, T.; Nakai, A.; Omiya, S.; Mizote, I.; Nakano, Y.; Higuchi, Y.; et al. Apoptosis signal-regulating kinase 1/p38 signaling pathway negatively regulates physiological hypertrophy. Circulation 2008, 117, 545-552.

23. Adams, R.H.; Porras, A.; Alonso, G.; Jones, M.; Vintersten, K.; Panelli, S.; Valladares, A.; Perez, L.; Klein, R.; Nebreda, A.R. Essential role of p38 $\alpha$ MAP kinase in placental but not embryonic cardiovascular development. Mol. Cell 2000, 6, 109-116.

24. O'Keefe, S.J.; Mudgett, J.S.; Cupo, S.; Parsons, J.N.; Chartrain, N.A.; Fitzgerald, C.; Chen, S.L.; Lowitz, K.; Rasa, C.; Visco, D.; et al. Chemical genetics define the roles of $\mathrm{p} 38 \alpha$ and $\mathrm{p} 38 \beta$ in acute and chronic inflammation. J. Biol. Chem. 2007, 282, 34663-34671.

25. Xie, J.; He, G.; Chen, Q.; Sun, J.; Dai, Q.; Lu, J.; Li, G.; Wu, H.; Li, R.; Chen, J.; et al. Syndecan 4 signaling is required for exercise-induced cardiac hypertrophy. Mol. Med. 2016. [CrossRef]

26. Watanabe, K.; Ma, M.; Hirabayashi, K.; Gurusamy, N.; Veeraveedu, P.T.; Prakash, P.; Zhang, S.; Muslin, A.J.; Kodama, M.; Aizawa, Y. Swimming stress in DN 14-3-3 mice triggers maladaptive cardiac remodeling: Role of p38 MAPK. Am. J. Physiol. Heart Circ. Physiol. 2007, 292, H1269-H1277.

27. Zabalgoitia, M.; Colston, J.T.; Reddy, S.V.; Holt, J.W.; Regan, R.F.; Stec, D.E.; Rimoldi, J.M.; Valente, A.J.; Chandrasekar, B. Carbon monoxide donors or heme oxygenase-1 (HO-1) overexpression blocks interleukin-18-mediated NF-kB-PTEN-dependent human cardiac endothelial cell death. Free Radic. Biol. Med. 2008, 44, 284-298. 
28. Liu, H.; Pedram, A.; Kim, J.K. Oestrogen prevents cardiomyocyte apoptosis by suppressing p38 $\alpha$-mediated activation of p53 and by down-regulating p53 inhibition on p38 $\beta$. Cardiovasc. Res. 2011, 89, 119-128.

29. Thandavarayan, R.A.; Watanabe, K.; Ma, M.; Gurusamy, N.; Veeraveedu, P.T.; Konishi, T.; Zhang, S.; Muslin, A.J.; Kodama, M.; Aizawa, Y. Dominant-negative p38 $\alpha$ mitogen-activated protein kinase prevents cardiac apoptosis and remodeling after streptozotocin-induced diabetes mellitus. Am. J. Physiol. Heart Circ. Physiol. 2009, 297, H911-H919.

30. Ruiz, M.; Coderre, L.; Lachance, D.; Houde, V.; Martel, C.; Legault, J.T.; Gillis, M.A.; Bouchard, B.; Daneault, C.; Carpentier, A.C.; et al. MK2 deletion in mice prevents diabetes-induced perturbations in lipid metabolism and cardiac dysfunction. Diabetes. 2016, 65, 381-392.

31. Liu, Z.; Cao, W. P38 mitogen-activated protein kinase: A critical node linking insulin resistance and cardiovascular diseases in type 2 diabetes mellitus. Endocr. Metab. Immune Disord. Drug Targets 2009, 9, 38-46.

32. Liang, Z.; Leo, S.; Wen, H.; Ouyang, M.; Jiang, W.; Yang, K. Triptolide improves systolic function and myocardial energy metabolism of diabetic cardiomyopathy in streptozotocin-induced diabetic rats. BMC Cardiovasc. Disord. 2015, 15, 42. [CrossRef]

33. Zhenzhong, Z.; Yafa, Y.; Jin, L. Fibrinogen-like protein 2 gene silencing inhibits cardiomyocytes apoptosis, improves heart function of streptozotocin-induced diabetes rats and the molecular mechanism involved. Biosci Rep. 2015, 35. [CrossRef]

34. Hao, P.; Yang, J.; Liu, Y.; Zhang, M.; Zhang, K.; Gao, F.; Chen, Y.; Zhang, C.; Zhang, Y. Combination of angiotensin-(1-7) with perindopril is better than single therapy in ameliorating diabetic cardiomyopathy. Sci. Rep. 2015, 5, 8794.

35. Li, C.J.; Lv, L.; Li, H.; Yu, D.M. Cardiac fibrosis and dysfunction in experimental diabetic cardiomyopathy are ameliorated by alpha-lipoic acid. Cardiovasc. Diabetol. 2012, 11, 73. [CrossRef]

36. Yu, W.; Zha, W.; Guo, S.; Cheng, H.; Wu, J.; Liu, C. Flos puerariae extract prevents myocardial apoptosis via attenuation oxidative stress in streptozotocin-induced diabetic mice. PLoS ONE 2014, 9, e98044.

37. Gilardini Montani, M.S.; Granato, M.; Cuomo, L.; Sandro, V.; di Renzo, L.; D’Orazi, G.; Faggioni, A.; Cirone, M. High glucose and hyperglycemic sera from type 2 diabetic patients impair dc differentiation by inducing ros and activating wnt/beta-catenin and p38 MAPK. Biochim. Biophys. Acta 2016, 1862, 805-813.

38. Ren, Y.; Shi, Y.; Wang, Y.; Li, Y.; Wu, S.; Li, H.; Zhang, Y.; Duan, H. P38 MAPK pathway is involved in high glucose-induced thioredoxin interacting protein induction in mouse mesangial cells. FEBS Lett. 2010, 584, 3480-3485.

39. Ki, Y.W.; Park, J.H.; Lee, J.E.; Shin, I.C.; Koh, H.C. JNK and p38 MAPK regulate oxidative stress and the inflammatory response in chlorpyrifos-induced apoptosis. Toxicol. Lett. 2013, 218, 235-245.

40. Boudina, S.; Abel, E.D. Diabetic cardiomyopathy revisited. Circulation 2007, 115, 3213-3223.

41. Zhao, Y.; Tan, Y.; Xi, S.; Li, Y.; Li, C.; Cui, J.; Yan, X.; Li, X.; Wang, G.; Li, W.; et al. A novel mechanism by which SDF-1 $\beta$ protects cardiac cells from palmitate-induced endoplasmic reticulum stress and apoptosis via CXCR7 and AMPK/p38 MAPK-mediated interleukin-6 generation. Diabetes 2013, 62, 2545-2558.

42. Yan, J.; Young, M.E.; Cui, L.; Lopaschuk, G.D.; Liao, R.; Tian, R. Increased glucose uptake and oxidation in mouse hearts prevent high fatty acid oxidation but cause cardiac dysfunction in diet-induced obesity. Circulation 2009, 119, 2818-2828.

43. Maillet, M.; van Berlo, J.H.; Molkentin, J.D. Molecular basis of physiological heart growth: Fundamental concepts and new players. Nat. Rev. Mol. Cell Biol. 2013, 14, 38-48.

44. Hsieh, Y.L.; Tsai, Y.L.; Shibu, M.A.; Su, C.C.; Chung, L.C.; Pai, P.; Kuo, C.H.; Yeh, Y.L.; Viswanadha, V.P.; Huang, C.Y. ZAK induces cardiomyocyte hypertrophy and brain natriuretic peptide expression via p38/JNK signaling and GATA4/c-Jun transcriptional factor activation. Mol. Cell. Biochem. 2015, 405, 1-9.

45. Hu, W.S.; Ho, T.J.; Pai, P.; Chung, L.C.; Kuo, C.H.; Chang, S.H.; Tsai, F.J.; Tsai, C.H.; Jie, Y.C.; Liou, Y.M.; et al. Gelsolin (GSN) induces cardiomyocyte hypertrophy and BNP expression via p38 signaling and GATA-4 transcriptional factor activation. Mol. Cell. Biochem. 2014, 390, 263-270.

46. Feng, B.; Chen, S.; George, B.; Feng, Q.; Chakrabarti, S. Mir133a regulates cardiomyocyte hypertrophy in diabetes. Diabetes Metab. Res. Rev. 2010, 26, 40-49.

47. Stanley, W.C.; Recchia, F.A.; Lopaschuk, G.D. Myocardial substrate metabolism in the normal and failing heart. Physiol. Rev. 2005, 85, 1093-1129. 
48. Harmancey, R.; Wilson, C.R.; Taegtmeyer, H. Adaptation and maladaptation of the heart in obesity. Hypertension 2008, 52, 181-187.

49. Zhang, K.; Li, L.; Qi, Y.; Zhu, X.; Gan, B.; DePinho, R.A.; Averitt, T.; Guo, S. Hepatic suppression of Foxo1 and Foxo3 causes hypoglycemia and hyperlipidemia in mice. Endocrinology 2012, 153, 631-646.

50. Qi, Y.; Xu, Z.; Zhu, Q.; Thomas, C.; Kumar, R.; Feng, H.; Dostal, D.E.; White, M.F.; Baker, K.M.; Guo, S. Myocardial loss of IRS1 and IRS2 causes heart failure and is controlled by p38 $\alpha$ MAPK during insulin resistance. Diabetes 2013, 62, 3887-3900.

51. Battiprolu, P.K.; Hojayev, B.; Jiang, N.; Wang, Z.V.; Luo, X.; Iglewski, M.; Shelton, J.M.; Gerard, R.D.; Rothermel, B.A.; Gillette, T.G.; et al. Metabolic stress-induced activation of Foxo1 triggers diabetic cardiomyopathy in mice. J. Clin. Investig. 2012, 122, 1109-1118.

52. Evans-Anderson, H.J.; Alfieri, C.M.; Yutzey, K.E. Regulation of cardiomyocyte proliferation and myocardial growth during development by Foxo transcription factors. Circ. Res. 2008, 102, 686-694.

53. Venkatakrishnan, C.D.; Tewari, A.K.; Moldovan, L.; Cardounel, A.J.; Zweier, J.L.; Kuppusamy, P.; Ilangovan, G. Heat shock protects cardiac cells from doxorubicin-induced toxicity by activating p38 MAPK and phosphorylation of small heat shock protein 27. Am. J. Physiol. Heart Circ. Physiol. 2006, 291, H2680-H2691.

54. Van Linthout, S.; Riad, A.; Dhayat, N.; Spillmann, F.; Du, J.; Dhayat, S.; Westermann, D.; Hilfiker-Kleiner, D.; Noutsias, M.; Laufs, U.; et al. Anti-inflammatory effects of atorvastatin improve left ventricular function in experimental diabetic cardiomyopathy. Diabetologia 2007, 50, 1977-1986.

55. Zuo, L.; Du, Y.; Lu, M.; Gao, J.; Hu, R.; Zhang, S.; Wang, Y.; Zhu, H.; Zhou, Q.; Wei, W.; et al. Atorvastatin inhibits hyperglycemia-induced expression of osteopontin in the diabetic rat kidney via the p38 MAPK pathway. Mol. Biol. Rep. 2014, 41, 2551-2558.

56. Ahad, A.; Ahsan, H.; Mujeeb, M.; Siddiqui, W.A. Gallic acid ameliorates renal functions by inhibiting the activation of 338 MAPK in experimentally induced type 2 diabetic rats and cultured rat proximal tubular epithelial cells. Chem. Biol. Interact. 2015, 240, 292-303.

57. Lv, G.F.; Dong, M.L.; Hu, D.H.; Zhang, W.F.; Wang, Y.C.; Tang, C.W.; Zhu, X.X. Insulin-mediated inhibition of p38 mitogen-activated protein kinase protects cardiomyocytes in severe burns. J. Burn. Care Res. 2011, 32, 591-599.

58. Fang, D.; Guan, H.; Liu, J.; Wei, G.; Ke, W.; Yao, B.; Xiao, H.; Li, Y. Early intensive insulin therapy attenuates the p38 pathway in the renal cortex and indices of nephropathy in diabetic rats. Endocr. J. 2012, 59, 81-90.

59. Bain, J.; Plater, L.; Elliott, M.; Shpiro, N.; Hastie, C.J.; McLauchlan, H.; Klevernic, I.; Arthur, J.S.; Alessi, D.R.; Cohen, P. The selectivity of protein kinase inhibitors: A further update. Biochem. J. 2007, 408, 297-315.

60. Komers, R.; Schutzer, W.; Xue, H.; Oyama, T.T.; Lindsley, J.N.; Anderson, S. Effects of p38 mitogen-activated protein kinase inhibition on blood pressure, renal hemodynamics, and renal vascular reactivity in normal and diabetic rats. Transl. Res. 2007, 150, 343-349.

61. Higham, A.; Lea, S.; Ray, D.; Singh, D. Corticosteroid effects on copd alveolar macrophages: Dependency on cell culture methodology. J. Immunol. Methods 2014, 405, 144-153.

62. Devaraj, S.; Venugopal, S.K.; Singh, U.; Jialal, I. Hyperglycemia induces monocytic release of interleukin-6 via induction of protein kinase $c-\alpha$ and $-\beta$. Diabetes 2005, 54, 85-91.

63. Turner, N.A.; Warburton, P.; O’Regan, D.J.; Ball, S.G.; Porter, K.E. Modulatory effect of interleukin-1 $\alpha$ on expression of structural matrix proteins, mmps and timps in human cardiac myofibroblasts: Role of p38 map kinase. Matrix Biol. 2010, 29, 613-620.

64. American Diabetes Association. Diagnosis and classification of diabetes mellitus. Diabetes Care 2014, 37, S81-S90.

65. Cheung, P.C.; Campbell, D.G.; Nebreda, A.R.; Cohen, P. Feedback control of the protein kinase TAK1 by SAPK2A/p38 $\alpha$. Embo J. 2003, 22, 5793-5805.

66. Coulthard, L.R.; White, D.E.; Jones, D.L.; McDermott, M.F.; Burchill, S.A. P38(MAPK): Stress responses from molecular mechanisms to therapeutics. Trends Mol. Med. 2009, 15, 369-379.

67. Cai, D.; Yuan, M.; Frantz, D.F.; Melendez, P.A.; Hansen, L.; Lee, J.; Shoelson, S.E. Local and systemic insulin resistance resulting from hepatic activation of IKK- $\beta$ and NF-KB. Nat. Med. 2005, 11, 183-190.

68. Ozcan, L.; Cristina de Souza, J.; Harari, A.A.; Backs, J.; Olson, E.N.; Tabas, I. Activation of calcium/calmodulin-dependent protein kinase II in obesity mediates suppression of hepatic insulin signaling. Cell Metab. 2013, 18, 803-815. 
69. Thandavarayan, R.A.; Giridharan, V.V.; Sari, F.R.; Arumugam, S.; Veeraveedu, P.T.; Pandian, G.N.; Palaniyandi, S.S.; Ma, M.; Suzuki, K.; Gurusamy, N.; et al. Depletion of 14-3-3 protein exacerbates cardiac oxidative stress, inflammation and remodeling process via modulation of MAPK/NF-KB signaling pathways after streptozotocin-induced diabetes mellitus. Cell. Physiol. Biochem. 2011, 28, 911-922.

70. Ozcan, L.; Xu, X.; Deng, S.X.; Ghorpade, D.S.; Thomas, T.; Cremers, S.; Hubbard, B.; Serrano-Wu, M.H.; Gaestel, M.; Landry, D.W.; et al. Treatment of obese insulin-resistant mice with an allosteric MAPKAPK2/3 inhibitor lowers blood glucose and improves insulin sensitivity. Diabetes 2015, 64, 3396-3405.

71. De Boer, J.F.; Dikkers, A.; Jurdzinski, A.; von Felden, J.; Gaestel, M.; Bavendiek, U.; Tietge, U.J. Mitogen-activated protein kinase-activated protein kinase 2 deficiency reduces insulin sensitivity in high-fat diet-fed mice. PLOS ONE 2014, 9, e106300.

72. Scharf, M.; Neef, S.; Freund, R.; Geers-Knorr, C.; Franz-Wachtel, M.; Brandis, A.; Krone, D.; Schneider, H.; Groos, S.; Menon, M.B.; et al. Mitogen-activated protein kinase-activated protein kinases 2 and 3 regulate serca2a expression and fiber type composition to modulate skeletal muscle and cardiomyocyte function. Mol. Cell. Biol. 2013, 33, 2586-2602.

73. Rajesh, M.; Batkai, S.; Kechrid, M.; Mukhopadhyay, P.; Lee, W.S.; Horvath, B.; Holovac, E.; Cinar, R.; Liaudet, L.; Mackie, K.; et al. Cannabinoid 1 receptor promotes cardiac dysfunction, oxidative stress, inflammation, and fibrosis in diabetic cardiomyopathy. Diabetes 2012, 61, 716-727.

74. Wold, L.E.; Ceylan-Isik, A.F.; Fang, C.X.; Yang, X.; Li, S.Y.; Sreejayan, N.; Privratsky, J.R.; Ren, J. Metallothionein alleviates cardiac dysfunction in streptozotocin-induced diabetes: Role of $\mathrm{Ca}^{2+}$ cycling proteins, NADPH oxidase, poly(ADP-ribose) polymerase and myosin heavy chain isozyme. Free Radic. Biol. Med. 2006, 40, 1419-1429.

75. Katz, M.G.; Fargnoli, A.S.; Williams, R.D.; Steuerwald, N.M.; Isidro, A.; Ivanina, A.V.; Sokolova, I.M.; Bridges, C.R. Safety and efficacy of high-dose adeno-associated virus 9 encoding sarcoplasmic reticulum $\mathrm{Ca}^{2+}$ adenosine triphosphatase delivered by molecular cardiac surgery with recirculating delivery in ovine ischemic cardiomyopathy. J. Thorac. Cardiovasc. Surg. 2014, 148, 1065-1072.

76. Talukder, M.A.; Yang, F.; Nishijima, Y.; Chen, C.A.; Kalyanasundaram, A.; Periasamy, M.; Zweier, J.L. Reduced SERCA2a converts sub-lethal myocardial injury to infarction and affects postischemic functional recovery. J. Mol. Cell. Cardiol. 2009, 46, 285-287.

77. Gurha, P.; Abreu-Goodger, C.; Wang, T.; Ramirez, M.O.; Drumond, A.L.; van Dongen, S.; Chen, Y.; Bartonicek, N.; Enright, A.J.; Lee, B.; et al. Targeted deletion of microRNA-22 promotes stress-induced cardiac dilation and contractile dysfunction. Circulation 2012, 125, 2751-2761.

78. Park, J.K.; Ronkina, N.; Hoft, A.; Prohl, C.; Menne, J.; Gaestel, M.; Haller, H.; Meier, M. Deletion of MK2 signalling in vivo inhibits small HSP phosphorylation but not diabetic nephropathy. Nephrol. Dial. Transplant 2008, 23, 1844-1853.

79. Oguiza, A.; Recio, C.; Lazaro, I.; Mallavia, B.; Blanco, J.; Egido, J.; Gomez-Guerrero, C. Peptide-based inhibition of IкB kinase/nuclear factor- $\mathrm{B}$ B pathway protects against diabetes-associated nephropathy and atherosclerosis in a mouse model of type 1 diabetes. Diabetologia 2015, 58, 1656-1667.

80. Hoshino, A.; Ariyoshi, M.; Okawa, Y.; Kaimoto, S.; Uchihashi, M.; Fukai, K.; Iwai-Kanai, E.; Ikeda, K.; Ueyama, T.; Ogata, T.; et al. Inhibition of p53 preserves parkin-mediated mitophagy and pancreatic $\beta$-cell function in diabetes. Proc. Natl. Acad. Sci. USA 2014, 111, 3116-3121.

81. Latronico, M.V.; Condorelli, G. MicroRNAs and cardiac pathology. Nat. Rev. Cardiol. 2009, 6, 419-429.

82. Van Rooij, E.; Sutherland, L.B.; Qi, X.; Richardson, J.A.; Hill, J.; Olson, E.N. Control of stress-dependent cardiac growth and gene expression by a microRNA. Science 2007, 316, 575-579.

83. Van Rooij, E.; Sutherland, L.B.; Thatcher, J.E.; DiMaio, J.M.; Naseem, R.H.; Marshall, W.S.; Hill, J.A.; Olson, E.N. Dysregulation of micrornas after myocardial infarction reveals a role of miR-29 in cardiac fibrosis. Proc. Natl. Acad. Sci. USA 2008, 105, 13027-13032.

84. Montgomery, R.L.; Hullinger, T.G.; Semus, H.M.; Dickinson, B.A.; Seto, A.G.; Lynch, J.M.; Stack, C.; Latimer, P.A.; Olson, E.N.; van Rooij, E. Therapeutic inhibition of miR-208a improves cardiac function and survival during heart failure. Circulation 2011, 124, 1537-1547.

85. Grueter, C.E.; van Rooij, E.; Johnson, B.A.; DeLeon, S.M.; Sutherland, L.B.; Qi, X.; Gautron, L.; Elmquist, J.K.; Bassel-Duby, R.; Olson, E.N. A cardiac microrna governs systemic energy homeostasis by regulation of MED13. Cell 2012, 149, 671-683. 
86. Romaine, S.P.; Tomaszewski, M.; Condorelli, G.; Samani, N.J. Micrornas in cardiovascular disease: An introduction for clinicians. Heart 2015, 101, 921-928.

87. Zhou, S.; Liu, Y.; Prater, K.; Zheng, Y.; Cai, L. Roles of microRNAs in pressure overload- and ischemia-related myocardial remodeling. Life Sci. 2013, 93, 855-862.

88. Shen, E.; Diao, X.; Wang, X.; Chen, R.; Hu, B. MicroRNAs involved in the mitogen-activated protein kinase cascades pathway during glucose-induced cardiomyocyte hypertrophy. Am. J. Pathol. 2011, 179, 639-650.

89. Tijsen, A.J.; van der Made, I.; van den Hoogenhof, M.M.; Wijnen, W.J.; van Deel, E.D.; de Groot, N.E.; Alekseev, S.; Fluiter, K.; Schroen, B.; Goumans, M.J.; et al. The microRNA-15 family inhibits the TGF $\beta$-pathway in the heart. Cardiovasc. Res. 2014, 104, 61-71.

90. Torella, D.; Ellison, G.M.; Torella, M.; Vicinanza, C.; Aquila, I.; Iaconetti, C.; Scalise, M.; Marino, F.; Henning, B.J.; Lewis, F.C.; et al. Carbonic anhydrase activation is associated with worsened pathological remodeling in human ischemic diabetic cardiomyopathy. J. Am. Heart Assoc. 2014, 3, e000434.

91. Blumensatt, M.; Greulich, S.; Herzfeld de Wiza, D.; Mueller, H.; Maxhera, B.; Rabelink, M.J.; Hoeben, R.C.; Akhyari, P.; Al-Hasani, H.; Ruige, J.B.; et al. Activin A impairs insulin action in cardiomyocytes via up-regulation of mir-143. Cardiovasc. Res. 2013, 100, 201-210.

92. Huang, B.; Qin, W.; Zhao, B.; Shi, Y.; Yao, C.; Li, J.; Xiao, H.; Jin, Y. MicroRNA expression profiling in diabetic gk rat model. Acta Biochim. Biophys. Sin. 2009, 41, 472-477.

93. Liu, S.; Li, W.; Xu, M.; Huang, H.; Wang, J.; Chen, X. Micro-RNA 21targets dual specific phosphatase 8 to promote collagen synthesis in high glucose-treated primary cardiac fibroblasts. Can. J. Cardiol. 2014, 30, 1689-1699.

94. Zhang, H.; Hao, Y.; Yang, J.; Zhou, Y.; Li, J.; Yin, S.; Sun, C.; Ma, M.; Huang, Y.; Xi, J.J. Genome-wide functional screening of mir-23b as a pleiotropic modulator suppressing cancer metastasis. Nat. Commun. 2011, 2, 554. [CrossRef]

95. Zhu, S.; Pan, W.; Song, X.; Liu, Y.; Shao, X.; Tang, Y.; Liang, D.; He, D.; Wang, H.; Liu, W.; et al. The microRNA miR-23b suppresses IL-17-associated autoimmune inflammation by targeting TAB2, TAB3 and IKK- $\alpha$. Nat. Med. 2012, 18, 1077-1086.

96. He, J.; Li, Y.; Yang, X.; He, X.; Zhang, H.; He, J.; Zhang, L. The feedback regulation of pi3k-miR-19a, and MAPK-mir-23b/27b in endothelial cells under shear stress. Molecules 2012, 18, 1-13.

97. Blumensatt, M.; Wronkowitz, N.; Wiza, C.; Cramer, A.; Mueller, H.; Rabelink, M.J.; Hoeben, R.C.; Eckel, J.; Sell, H.; Ouwens, D.M. Adipocyte-derived factors impair insulin signaling in differentiated human vascular smooth muscle cells via the upregulation of miR-143. Biochim. Biophys. Acta 2014, 1842, 275-283.

98. Qian, L.; Van Laake, L.W.; Huang, Y.; Liu, S.; Wendland, M.F.; Srivastava, D. miR-24 inhibits apoptosis and represses BIM in mouse cardiomyocytes. J. Exp. Med. 2011, 208, 549-560.

99. Zampetaki, A.; Kiechl, S.; Drozdov, I.; Willeit, P.; Mayr, U.; Prokopi, M.; Mayr, A.; Weger, S.; Oberhollenzer, F.; Bonora, E.; et al. Plasma microrna profiling reveals loss of endothelial miR-126 and other microRNAs in type 2 diabetes. Circ. Res. 2010, 107, 810-817.

100. Xiang, Y. miR-24 in diabetes. Oncotarget 2015, 6, 16816-16817.

101. Kiriakidou, M.; Nelson, P.T.; Kouranov, A.; Fitziev, P.; Bouyioukos, C.; Mourelatos, Z.; Hatzigeorgiou, A. A combined computational-experimental approach predicts human microRNA targets. Genes Dev. 2004, 18, $1165-1178$.

102. Huang, W.; Tian, S.S.; Hang, P.Z.; Sun, C.; Guo, J.; Du, Z.M. Combination of microRNA-21 and microRNA-146a attenuates cardiac dysfunction and apoptosis during acute myocardial infarction in mice. Mol. Ther. Nucleic Acids 2016, 5, e296.

103. Zaman, M.S.; Shahryari, V.; Deng, G.; Thamminana, S.; Saini, S.; Majid, S.; Chang, I.; Hirata, H.; Ueno, K.; Yamamura, S.; et al. Up-regulation of microRNA-21 correlates with lower kidney cancer survival. PLoS ONE 2012, 7, e31060.

(C) 2016 by the authors; licensee MDPI, Basel, Switzerland. This article is an open access article distributed under the terms and conditions of the Creative Commons Attribution (CC-BY) license (http://creativecommons.org/licenses/by/4.0/). 